Journal of Social Sciences 4 (2): 75-79, 2008

ISSN 1549-3652

(C) 2008 Science Publications

\title{
Reconsidering the Understanding of Technoscientific Knowledge
}

\author{
Charalambos Tsekeris and Ioannis Katerelos \\ Department of Psychology, Panteion University of Social and Political Sciences, 136 Syngrou \\ Ave., 176 71, Athens, Greece
}

\begin{abstract}
Nowadays, science and technology have immediate and powerful social impacts. Therefore, their systematic study is not possible without attention to questions of citizenship and democracy. Building upon this critical discussion, the present paper seeks to provide a comprehensive overview of the changes in the lay and expert understanding of technoscientific knowledge. The presentation and analysis of these changes is mainly conceived in terms of significant sociological issues: the logic of the "public understanding of science", the search for alternative technological projects and the radical reconstruction of "expertise" and "knowledge politics". The necessity to adequately address these issues is vital for the future of civil society and the quality of our everyday life.
\end{abstract}

Keywords: Science, technology, knowledge politics, expertise and citizenship

\section{INTRODUCTION}

For almost two centuries, the "enlightenment" teleological conceptions of Reason and cumulative Progress (as normative ends in their own right) have overwhelmingly dominated Eurocentric governance discourses on science and technology, and unreflexively attained an indisputably hegemonic status ${ }^{[1]}$. In the wide context of the sociology of scientific knowledge (SSK) and the social studies of technology, it is rather customary to play off a familiar "model" which is often used to negatively characterize Modernity and its positivistic origins: The deficit model of the public understanding of science.

In accordance with this elitist model, the "heroic" individual scientist and the scientific community as a whole, possess "rare", "novel" and "unique" knowledge about matters unknown to the larger audience of non-scientists or non-experts, and their primary professional and moral task is to adequately address that deficit by conveying suitablyfashioned knowledge to the recipients, who either possess no knowledge on the relevant subject or live with "prenotions" (Emile Durkheim) that the new knowledge aims to supplement and correct. In this line, technology is the field that practically applies or uses that positive knowledge, against ignorance and ideological defensiveness.
Increasingly, however, we are witnessing the open celebration of the interactional accommodation, mutual adjustment, or hybridization, of "situated" and "contextual" knowledges, as well as the emergence of the new local blocs and groupings which dynamically enter the contested terrain of "truth". Recent discussions of governance in relation to science and technology most commonly include various considerations of how to make these fields publicly accountable in the context of on-going demands for greater transparency. This mainly focuses on policy, legislation and regulation matters, and the establishment of new reflexive frameworks of public representation, participation or consultation.

The logic of the public understanding of science: According to the old positivistic "social engineering" approach, ordinary citizens are to be made scientifically literate by filling the aforementioned "deficit" in their knowledge and appreciation of the scientific project. As the postmodern age struggles to effectively make the transition out of the technocratic heritage of the 20th Century, the project of undoing any arrogant "deficit attitude" is increasingly appearing as an everyday practical task. Only if we can concretize the issues on the technical and ethical terrain will that transition succeed. Then, we will find out what it really means to live and create in a technological society ${ }^{[2]}$.

Corresponding Author:

Charalambos Tsekeris, Department of Psychology, Panteion University of Social and Political Sciences, Athens, Greece 
But science has also to be communicated in a way that, in the last instance, recognizes and acknowledges the relevant individual and social contexts. So, alongside the well-established modern confidence that science had the answers to almost everything ( 50 years or so ago, there was indeed a great deal of certainty, confidence and optimism that science and technology could provide ready solutions to solve all social problems), came a much more sceptical turn: relations between some elements of the scientific community and those they considered to be part of an "anti-science movement" reached the level of open warfare.

Since the advent of the so-called Public Understanding of Science movement in the UK 20 years ago, there has been a significant growth in practical activities (media training workshops, presentation skills and popular writing courses) to improve the communication skills of both social and natural scientists - that is, their ability to adequately communicate with society and, in general, to foster communication exchange. But this growth is also addressing changes in the nature and character of policy decision-making processes, where scientists should openly recognise that there are many other voices in society with different and conflicting, yet legitimate, viewpoints.

There has been also a particular increase in the use of participatory methods, where the need for critical social learning is indispensable. The director of the Rathenau Institute for Technology Assessment (the Netherlands) has argued that what is now important is 'to widen the debate, to take citizens' perspectives into account and to inform experts of the questions uninitiated people are asking and the reasons that lie behind them" [3]. In the same line, the Danish Board of Technology (established in 1985) has adopted similar public participatory methods to enhance "practical" or "lay" wisdom, experiences and visions ${ }^{[4]}$.

Furthermore, there is a widespread sense of growing levels of public mistrust in science and technology policy and regulation. The UK House of Lords "Science and Society" report identifies a general "crisis of confidence" in science and maintains that policy-makers "will find it hard to win public support on any issue with a science component, unless the public's attitudes and values are recognised, respected and weighed along with the scientific and other factors" [5].

The UK's BSE "scandal" of the mid-1980s to mid-1990s has been often cited as pivotal to the change of direction noted in the relations between science, technology and citizenship. A key moment here was the publication of the 2000 House of Lords Report Science and Society, followed a year later by the European Commission's Science and Society Action Plan. So, now that science has ceased to enjoy unquestioned authority, there is a vital need for a new agenda, for the reflexive inclusion of social, economic, environmental and ethical considerations to achieve a balanced appraisal.

No doubt, technoscience and its products are promiscuously intersecting with historically relevant, socially constructed and culture-bound human beliefs and values. As technoscience encroaches more closely on heavily value-laden issues, members of the wider public are arguably claiming a stronger role in both the regulation of science and the shaping of the research agenda. Hence, it is generally acknowledged that technoscience, society and culture are essentially intertwined (and only analytically separated).

Complexity, performativity, pluralism and context-dependency are basic characteristics of the contemporary condition of knowledge. These characteristics are increasingly leading to a dynamic blurring of actor identities. According to Alan Irwin and Mike Michael, the wider public is already "highly knowledgeable in ways that could fruitfully inform scientific assessment ... there is a blurring of expert and lay knowledge ... both 'public' and 'science' no longer stand as discrete entities..." [6]

It is also no longer self-evident and universally accepted that the general public trusts and follows the conclusions of science and technology. The public is thus becoming more and more critical and suspicious; it therefore actively demands a substantial role in the democratic development of science and technology. Public acceptance is always needed, especially when scientific debates concern issues of health and food.

The search for alternative technological projects: Various "social voices" are now brought right at the central stage of agenda-setting and decision-making processes, towards an innovative "citizen science" (Alan Irwin) where common grounds are persistently pursued through open, rational discourse: "If the decision-making process in matters related to applied science is constructed in such a way that the interests of the majority are clearly articulated and represented, it is likely that we are going to move in an apophatic direction" ${ }^{[7]}$.

On the other hand, if private or corporate interests finally manage to gain a hegemonic position, we are going to continue in the present promethean (or 
non-apophatic) mode. Therefore, the issue of the "democratic rationalization" (Andrew Feenberg) of technoscience should not be naively marginalized or underestimated; instead, it rather belongs to the heart of any contemporary project for the radical revision, revival and technological sensitization of the public sphere, as optimistically defined by Jurgen Habermas.

For many critical scholars, we additionally need a kind of technology which is efficiently responsive to the dangerously increasing environmental risks, hazards and change - that is, alternative technological projects, such as clean energy, recyclable resources, hybrid vehicles, etc. Promethean technology cannot lead us out of the current crisis; on the contrary, it profoundly re-constitutes the very rationality which continues to create an exploitative and myopic (shortsighted) approach to the natural world (by seeking human security and happiness via domination and utilitarian control over nature).

That is why a strategic emphasis should be rigorously placed upon the constantly increasing number of "post-modern" technologies, which possess a more democratic and humane character - that means, a weaker, "apophatic character" (Nicos Mouzelis). The non-promethean type of technology (e.g. anti-pollution technologies) is particularly linked to the modest and humble goals of restoring natural balances and harmonies, as well as the Self-Nature relationship, against the Western classical power talk.

Interrogating expertise: Moreover, these exciting sociocultural and intellectual developments had a profound impact upon the very nature, character and content of the notion of technoscientific "expertise", as well as upon the main principles for public engagement and participation in technoscientific decision-making. Drawing heavily upon the famous Collins/Evans's typology, Sheila Jasanoff briefly summarizes the historicity of this hotly debated phenomenon and moves the centre of our analytic gravity towards the three main stages, or "Waves", that strongly characterize the changing status of expertise ${ }^{[8]}$ :

- Wave One is identified with the era of positivism, in which "expertise was taken for granted and hence quite unproblematic. Science was thought to be esoteric and authoritative, and, in a corollary later found unacceptable, any person who embodied 'good science' was permitted to hold forth unchallenged as an expert in his (rarely her) field of knowledge".

- Wave Two is identified with the era of unrestrained and uncritical social constructivism, in which "relativism about the foundations of expert knowledge reigned supreme; this led ... to the equally unstable conclusion that all technical decision-making should be wide open to public participation".

- Wave Three is identified with the contemporary era, in which "we need to recognize that there is legitimate expertise on technical issues; not everybody can or should hope to participate in all aspects of technical deliberation; and the demarcation between science and politics, so enthusiastically dissolved by Wave Two scholars, should be at least partly reinstated".

According to the so-called "Third Wave", public involvement in technoscientific decision-making processes should be always regarded as a contextual and empirically open issue. It is also stressed the vital need for better conceptual and methodological tools in order to accurately and rigorously determine "how much is 'just right' in any given situation" (Jasanoff).

The necessity to act collectively: By theoretically reflecting on the varying and complex relationships between science and society (including politics), we can of course discern critical issues which are increasingly at the forefront of contemporary intellectual life and public debate. In recent years, indeed, the various critiques of technocratic forms of science and technology policy systematically point out the vital and urgent need for more accountable, dialogical and participatory decision processes. However, this normative democratic call for more public participation and transparency, as well as for opening up the processes of scientific knowledge-production, should comprehensively move out of its own short-sighted context. In other words, a critical broadening of science and technology studies should be alternatively set forth beyond the narrow question of public participation and engagement.

What is really needed is to always keep a sharp critical eye to the wider financial and political contexts of science and technology, so that we can possibly apply new emancipative policies and decisively escape from today's dominant debilitating discourses, in a largely uncaring "world risk society" (Ulrich Beck). For example, the various risks and potentialities of the rapid developments on artificial life and intelligence, genetics and nanotechnology, or biomedicine and biotechnology, cannot be fully grasped without thinking more globally, in the crucial reflexive direction of new areas of study and new forms of radical egalitarian action. 
Therefore, more sociological emphasis should be carefully put on the global implications of science and technology, as well as on the new emerging alliances between technoscience, the public and the state, in order to effectively orientate the rapidly increasing volume of new knowledge towards societal and human betterment. The urgent necessity to "act collectively" ultimately entails that technopolitics enters the complex socio-political terrain of the $21^{\text {st }}$ century, as an agonistic intersection of politics and technology, or as a self-conscious "strategic practice of designing or using technology to constitute, embody, or enact political goals" ${ }^{[9]}$. In the context of contemporary infosociety and cyberculture, technopolitics as a technologically mediated form of political engagement and action is a radical tool potentially available to oppositional, oppressed or excluded, social groups and communities ${ }^{[10]}$. It is thus an important means of consciousness-raising and empowerment.

Delineating a new politics of science and technology: In this policy-oriented level, the notion of knowledge politics involves the governance of the life-altering, anticipated (rather than actual) consequences of the proliferation of new scientific and technical knowledge for modern society, as well as the possibility to (participatively rather than in isolation) control the use and "consumption" of that knowledge, in a democratizing direction ${ }^{[11]}$. In this respect, knowledge politics (Wissenpolitik) amounts to a wholly new field of political activity in contemporary information societies, aimed at critically regulating the complex development and use of novel scientific and technical knowledge (including test-tube human conception, reproductive cloning, genetically engineered foods, nanotechnology, genetic engineering, etc.). In the same line, Steve Fuller's innovative project of social epistemology desperately calls for a radically politicized expertise and a reflexively open, rational administration of knowledge-production processes ${ }^{[12]}$.

From this groundbreaking viewpoint, knowledge politics becomes deeply attuned to the intimate logic of the policy-making arena, where matters of fact are inextricably linked to political and societal goals and choices. Such a logic inevitably turns technoscience into a more complex and less autonomous social institution, while demonstrating its Janus-faced character. That is, some scholars believe that this seriously threatens its integrity and emancipatory potential; others think that it significantly enriches it, and re-integrates science into the very fabric of democratic debate.
Knowledge politics, at the science and technology policy level, requires a relative decrease in the unbridled academization and hastening of knowledge-production ${ }^{[13]}$, as well as radically new communication methods and public participation activities. It also involves the "contingent" character of the realization of truth and an "agonistic" attempt to increase technoscience's sphere of public accountability. Of course, this entails further reflexive inquiries into the "what", "who" and "how" of technoscientific knowledge-production, in a changing context of increasing globalization.

\section{CONCLUSION}

Technoscience is now seen as dialectically interrelated with the social structure rather than as independent of it ${ }^{[14]}$. Technology/science and society/culture mutually and synergistically form an inseparable pair (neither is intelligible without reference to each other). Recent theorizations of technoscientific knowledge and its public understanding have gradually taken an empirical turn away from the transcendental orientation of early philosophy of science and technology, toward a more practical, contextual, discursive and ethical interpretation.

Such an interpretation intimately involves a careful critical reflection upon the socially responsible treatment of scientific information and the specific operating principles of "scientific democracy", as well as upon the essential indivisibility of technoscience and citizenship. Ultimately, a further "improved understanding" of technoscience, as anticipated by the 1985 report of the Royal Society, would be of high value in terms of ${ }^{[15]}$ :

- $\quad$ national prosperity

- economic performance

- public policy

- personal decisions

- everyday life

- $\quad$ risk and uncertainty

- contemporary thought and culture

\section{REFERENCES}

1. Mokyr, J., 1990. The Lever of Riches: technological creativity and economic progress. New York: Oxford University Press.

2. Feenberg, A., 1999. Questioning Technology. Routledge: New York. 
3. European Commission, 2000. Science and Governance in a Knowledge Society: the challenge for Europe. In: Discussion report on Session One: Science, Citizens and the Decision-Making Process. Brussels.

4. Klüver, L., 1995. Consensus Conferences at the Danish Board of Technology. In: Simon Joss and John Durant (eds.), Public Participation in Science: the role of consensus conferences in Europe. London: Science Museum, pp: 41-49.

5. UK House of Lords, 2000. Science and Society. London: Third Report of the Select Committee on Science and Technology.

6. Irwin, A. and M. Michael, 2003. Science, Theory and Public Knowledge. Maidenhead: Oxford University Press, p: 111.

7. Mouzelis, N., 1997. Religious Neoliberalism. To Vima, 02/11/1997, p: B01.

8. Jasanoff, S., 2003. Breaking the Waves in Science Studies: Comment on Evans and Collins. Social Studies of Science, 33(3), p: 390.
9. Hecht, G., 1998. The Radiance of France: Nuclear Power and National Identity after World War II. Cambridge: MIT Press, p: 15.

10. Kellner, D., 1997. Intellectuals, the New Public Spheres, and Technopolitics. New Political Science, 41-42, pp: 169-188.

11. Stehr, N., 2005. Knowledge Politics: Governing the Consequences of Science and Technology. Boulder, CO: Paradigm Publishers.

12. Fuller, S., 1988. Social Epistemology. Bloomington: Indiana University Press.

13. Pels, D., 2003. Unhastening Science. Liverpool: Liverpool University Press.

14. Tsekeris, C., 2007. Technology as Politics. Ubiquity, 8(37).

15. Irwin, A., 1995. Citizen Science. A Study of People, Expertise and Sustainable Development. London: Routledge, p: 13. 